\title{
Resources for the attention of patients with breast cancer in Mexico
}

\author{
Enrique Bargalló-Rocha1 , Eva Ruvalcaba-Limón", Gregorio Quintero-Beuló3, \\ Jaime Alonso Reséndiz-Colosia ${ }^{4}$, Efraín Salas-González ${ }^{5}$, Juan Alberto Serrano-Olvera ${ }^{6}$, \\ Alejandro Silva-Juan ${ }^{4}$, Antonio Maffuz-Aziz ${ }^{6}$, Pedro Figueroa-Martínez ${ }^{7}$, Ricardo Villalobos-Valencia ${ }^{8}$, \\ Cynthia Villarreal-Garza ${ }^{9}$, Servando Cardona-Huerta ${ }^{9}$, Rodrigo Serrano-Ortiz ${ }^{10}$, Amelia Rodríguez-Trejo ${ }^{11}$, \\ Adolfo Eduardo Barragán-Curiel ${ }^{12}$ and Sergio Rodríguez-Cuevas ${ }^{13}$
}

${ }^{1}$ Department of Breast Tumors, Instituto Nacional de Cancerología de México, Ciudad de México; ${ }^{2}$ Department of Breast Surgical Oncology, Institute of Breast Diseases, FUCAM, A.C., Ciudad de México; ${ }^{3}$ Oncology Department Breast Tumors Unit, Hospital General de México Dr. Eduardo Liceaga, Ciudad de México; ' ${ }^{4}$ Breast Tumors Unit, Centro Médico Nacional (CMN) Siglo XXI, Instituto Mexicano del Seguro Social (IMSS), Ciudad de México; ${ }^{5}$ Department of Medical Oncology, CMN Occidente, IMSS, Guadalajara, Jalisco; ${ }^{6}$ Private practice, Cancer Center, Centro Médico ABC, Ciudad de México; ${ }^{7}$ Chemotherapy Unit and Oncology Outpatient Services, Specialty Clinic, Hospital General del Instituto de Seguridad y Servicios Sociales de los Trabajadores del Estado (ISSSTE), San Luis Potosí, San Luis Potosi; ${ }^{8}$ Department of Medical Oncology, CMN La Raza, IMSS, Ciudad de México; ${ }^{9} \mathrm{Clinical}$ Oncology, Hospital San José and Hospital Zambrano Hellion, Tecnológico de Monterrey, Nuevo León; ${ }^{10}$ State Oncology Center, Instituto de Seguridad Social del Estado de México y Municipios, Toluca, Estado de México; ${ }^{11}$ General director of Centro Estatal de Cancerología Nayarit, Tepic, Nayarit; ${ }^{12}$ Nuevo Hospital Civil de Guadalajara Juan I. Menchaca, Guadalajara, Jalisco; ${ }^{13}$ General Coordinator of the Mexican Cooperative Research Groups in Oncology-SMeO, Ciudad de México. Mexico

\begin{abstract}
Multicenter studies on breast cancer require inter-institutional collaboration, resources and specialized personnel. In Mexico, many institutions provide these services, but their information is not accessible; to mitigate it, the Mexican Society of Oncology formed the Mexican Cooperative Research Groups in Oncology. Objective: To describe the infrastructure, personnel and activities of hospitals with care of patients with breast cancer in Mexico. Methods: A survey was conducted to 30 breast cancer specialists about resources and services of their institutions. Results: $13(43.3 \%)$ specialists answered the survey, $38.5 \%$ of Seguro Popular, $23.1 \%$ of Instituto Mexicano del Seguro Social, and $38.4 \%$ of other institutions, with a median of 300 (50-950) new cases per year. All the institutions have oncological surgery, breast radiology, palliative care, pathology, nutrition and multidisciplinary sessions. All have ultrasound with breast transducer, 92.3\% digital mammography, and 53.8\% tomosynthesis and/or magnetic resonance. They do sentinel lymph node detection with dye (92.3\%) or radionuclide (61.5\%). Tamoxifen, aromatase inhibitors and trastuzumab are available in $92.3 \%$, and other target therapies in $<40 \%$. Genetic signatures are done in $21.3 \%$ and $61.5 \%$ analysis of hereditary cancer. Conclusions: The institutional capacity to participate in multicenter studies is heterogeneous; the few resources in several institutions limit their inclusion to studies of breast cancer.
\end{abstract}

Key words: Infrastructure. Services. Quality of attention. Breast cancer. Mexico.

\section{Correspondence:}

*Eva Ruvalcaba-Limón

E-mail: evaruvalcaba@yahoo.com.mx

1665-9201/@ 2019 Sociedad Mexicana de Oncología. Published by Permanyer México. This is an Open Access article under the terms of the CC BY-NC-ND
Available online: 13-09-2019

Gac Mex Oncol. 2019;19:27-32

www.gamo-smeo.com

license (http://creativecommons.org/licenses/by-nc-nd/4.0/). 


\section{Introduction}

Breast cancer is the most common neoplasm and with the highest mortality in women worldwide; 2012 estimates revealed a global incidence of 1.67 million new cases and 522,000 deaths associated with this disease ${ }^{1}$. In Mexico, 6,273 breast cancer deaths were recorded in women in 2015, which accounted for $14.3 \%$ of total deaths in females that year in our country ${ }^{2}$.

The factors with the highest impact on the survival of patients with this important disease are timely detection, clinical stage and optimal treatment ${ }^{3,4}$. In developed countries, 5 -year survival can be as high as $80 \%$, while in developing countries, it is not higher than $40 \%{ }^{5}$.

The Mexican Society of Oncology (SMeO - Sociedad Mexicana de Oncología, A.C.) is an association that groups together specialists in the diagnosis, treatment and prevention of cancer in Mexico. Its goals include the promotion of applied research in a coordinated, inter-institutional and multidisciplinary way, with this task concurring with some aspects of the inter-institutional proposal of the National Plan for Cancer $\mathrm{Control}^{6}$. To this aim, SMeO created the Mexican Cooperative Research Groups in Oncology (GCIMO - Grupos Cooperativos de Investigación de México en Oncología) for several subspecialties, including breast cancer (GCIMO-M). The present study is a result of the GCIMO-M collaborative work. It is about a survey by means of which a situational diagnosis of the characteristics and resources of 13 centers specialized in the care of patients with breast cancer in Mexico, with the purpose to know the potential of each institution to be included in research projects according to the requirements of each research protocol.

\section{Material and methods}

Between March 2017 and February 2018, a cross-sectional, descriptive, observational study was carried out by means of a 68-question survey, which was electronically distributed to breast cancer specialists from institutions that treat patients with this pathology in Mexico, who provided the requested information and answered by the same route. In order to be included in the study, the surveyed subjects had to be $\mathrm{SMeO}$ active members and agree to participate.

The questions included collected general information on the respondent, and explored the characteristics of the institution where he/she works, in particular regarding the resources available for the care of patients with breast cancer, which were grouped as follows:
- Characteristics of care at the institution.

- Human resources, services and equipment for diagnosis and care.

- Targeted and hormone therapies.

- Activities related to therapeutic decisions.

- Liaison, research and training of human resources activities.

With the collected information, a database was integrated and analyzed with the SPSS ${ }^{\circledR}$ program.

The survey is presented in table S1 of the supplemental material that accompanies this article.

\section{Results}

The survey was submitted to 30 specialists, out of which 13 (43.3\%) answered with information about an equal number of institutions in 6 States of the Mexican Republic (Table 1).

Median breast cancer new cases of the participating institutions was 300 patients per year (range: 50-950). Ten institutions (76.9\%) referred having databases for cases to be reported (three had incomplete databases) and three $(23.1 \%)$ did not. The database of hospitals belonging to the Mexican Institute of Social Security (IMSS - Instituto Mexicano del Seguro Social) is its own institutional epidemiological registry. Regarding affiliation, most institutions are covered by the Seguro Popular (People's Insurance) (5/13 [38.46\%]), followed by IMSS (3/13 [23.07\%]), private institutions not covered by Seguro Popular (2/13 [15.38\%]), the Institute of Social Security and Services for State Workers (ISSSTE - Instituto de Seguridad Social y Servicios para los Trabajadores del Estado) (1/13 [7.7\%]), the Institute of Social Security of the State of Mexico and Municipalities (ISSEMyM - Instituto de Seguridad Social del Estado de México y Municipios) (1/13 [7.7\%]) and one hospital of the Ministry of Health not covered by Seguro Popular (1/13 [7.7\%]).

As for human resources for the care of patients, only three institutions (23.1\%), all of them in Mexico City, referred having all the specialists in the care team (surgical oncology, medical oncology, radiation oncology, breast radiology, rehabilitation, palliative care, plastic surgery, pathology, genetics, psycho-oncology and nutrition). The specialties that all institutions have (in-house or outsourced) were surgical oncology (surgical oncologist and/or gynecologic oncologist), breast radiology, palliative care, pathology and nutrition. The less common specialist in the institutions was the geneticist, who is only present in seven $(53.8 \%)$; the 
Table 1. Institution where specialists who participated in the survey work

\begin{tabular}{|l|l|}
\hline City, State & Institution \\
\hline Mexico City & Instituto Nacional de Cancerología de México \\
\hline & Instituto de Enfermedades de la Mama (IEM) - FUCAM \\
\hline & Hospital General de México Dr. Eduardo Liceaga \\
\hline Centro de Cáncer, Centro Médico ABC \\
\hline Hospital de Oncología, Centro Médico Siglo XXI - IMSS \\
\hline Guadalajara, Jal. & Hospital de Ginecoobstetricia n. ${ }^{\circ}$ 3, Centro Médico Nacional La Raza - IMSS \\
\hline San Luis Potosí, SLP & Centro Médico Nacional de Occidente - IMSS \\
\hline Toluca, State of Mexico & Nuevo Hospital Civil de Guadalajara Juan I. Menchaca \\
\hline Monterrey, NL & Clínica de Especialidades, Hospital General ISSSTE \\
\hline Tepic, Nay. & Centro Oncologico Estatal, ISSEMyM \\
\hline
\end{tabular}

FUCAM (Fundacion de Cancer de Mama): Breast Cancer Foundation; ABC: American British Cowdray; IMSS (Instituto Mexicano del Seguro Socia): Mexican Institute of Social Security; ISSSTE (Instituto de Seguridad Social y Servicios para los Trabajadores del Estado): Institute of Social Security and Services for State Workers; ISSEMYM (Instituto de Seguridad Social del Estado de Mexico y Municipios): Institute of Social Security of the State of Mexico and Municipalities.

remaining centers that do not have this specialty, cannot outsource it either (Table 2).

Regarding the equipment for patient diagnosis, all institutions referred having ultrasound with breast transducer and guided excisional biopsies with breast marking (with harpoon or on the skin); only three (23.1\%) have analog mammography and the majority (12 [92.3\%]) have digital mammography; currently, most of them have a linear accelerator, and there is still an institution with access to a cobalt- 60 machine by outsourcing (Table 3).

The assessment of drug availability revealed that almost all (12/13 [92.3\%]) have trastuzumab available, whereas the rest of the targeted therapies were irregularly available in the institutions (Table 4). The two hormone therapies with the highest availability were tamoxifen and aromatase inhibitors (both in 12/13 [92.3\%]). No single drug was available in all institutions, and neither was there any institution that had all drugs available (Table 4).

To complement the diagnoses and establish patient treatment, eight institutions (61.5\%) answered that they do have genetic testing for hereditary cancer and most of them referred not having genetic testing available to support treatment decisions (Table 5).
Table 2. Availability of human resources in the institutions

\begin{tabular}{|l|c|c|c|}
\hline \multirow{2}{*}{ Specialist } & \multicolumn{3}{|c|}{ Availability (n = 13), n (\%) } \\
\cline { 2 - 4 } & Yes & No & Outsourced \\
\hline Surgical oncology & $13(100)$ & - & - \\
\hline Medical oncology & $12(92.3)$ & $1(7.7)$ & - \\
\hline Radiation oncology & $10(76.9)$ & $1(7.7)$ & $2(15.4)$ \\
\hline Breast radiology & $11(84.6)$ & - & $2(15.4)$ \\
\hline Rehabilitation & $9(69.2)$ & $3(23.1)$ & $1(7.7)$ \\
\hline Palliative care & $12(92.3)$ & - & $1(7.7)$ \\
\hline Plastic surgery & $9(69.2)$ & $2(15.4)$ & $2(15.4)$ \\
\hline Pathology & $12(92.3)$ & - & $1(7.7)$ \\
\hline Genetics & $7(53.8)$ & $6(46.1)$ & - \\
\hline Psycho-oncology & $10(76.9)$ & $2(15.4)$ & $1(7.7)$ \\
\hline Nutrition & $13(100)$ & - & - \\
\hline
\end{tabular}

Most institutions referred holding multidisciplinary sessions for therapeutic decision, with a median of one session per week; only three institutions informed on the number of attendees to the sessions, with a median of five participants. 
Table 3. Equipment and services available in the institutions

\begin{tabular}{|c|c|c|c|}
\hline & \multicolumn{3}{|c|}{ Availability ( $=13), n(\%)$} \\
\hline & Yes & No & Outsourced \\
\hline Analog mammography & $3(23.1)$ & $10(76.9)$ & - \\
\hline Digital mammography & $12(92.3)$ & - & $1(7.7)$ \\
\hline Tomosynthesis & $7(53.8)$ & $6(46.1)$ & - \\
\hline Ultrasound with breast transducer & $13(100)$ & - & - \\
\hline Magnetic resonance imaging (with with breast antenna) & $7(53.8)$ & $2(15.4)$ & $4(30.7)$ \\
\hline Gamma camera (gamma probe) & $8(61.5)$ & $5(38.4)$ & - \\
\hline Radionuclide lymphatic mapping & $8(61.5)$ & $5(38.4)$ & - \\
\hline Lymphatic mapping with dye & $12(92.3)^{*}$ & $1(7.7)^{\dagger}$ & - \\
\hline Immunohistochemistry & $12(92.3)$ & - & $1(7.7)$ \\
\hline Ultrasound-guided biopsy & $11(84.6)$ & $1(7.7)$ & $1(7.7)$ \\
\hline Stereotactic-guided biopsy (cut \pm aspiration) & $11(84.6)$ & $1(7.7)$ & $1(7.7)$ \\
\hline Breast marking-guided biopsy & $13(100)$ & - & - \\
\hline Linear accelerator for radiation therapy & $10(76.9)$ & $1(7.7)$ & $2(15.4)$ \\
\hline Radiotherapy planning system & $10(76.9)$ & $1(7.7)$ & $2(15.4)$ \\
\hline Cobalt-60 machine & - & $12(92.3)$ & $1(7.7)$ \\
\hline Tissue bank & $7(53.8)$ & $6(46.1)$ & - \\
\hline Biological sample bank & $5(38.4)$ & $8(61.5)$ & - \\
\hline
\end{tabular}

*In one institution, the doctor obtains it outside the hospital. ${ }^{\dagger}$ Trained specialists, difficulty to obtain the dye, in addition to its high cost and few cases at early stages.

Table 4. Drug availability in the institutions

\begin{tabular}{|l|c|c|c|}
\hline \multirow{2}{*}{ Drug } & \multicolumn{3}{|c|}{ Availability (n= 13), n (\%) } \\
\cline { 2 - 4 } & Yes & No & Outsourced \\
\hline $\begin{array}{l}\text { Targeted therapies } \\
\text { Trastuzumab }\end{array}$ & $12(92.3)$ & $1(7.7)$ & - \\
$\begin{array}{l}\text { Lapatinib } \\
\text { Pertuzumab }\end{array}$ & $7(53.8)$ & $6(46.1)$ & - \\
\hline $\begin{array}{l}\text { Trastuzumab + } \\
\text { Emtansine (DM1) }\end{array}$ & $5(38.4)$ & $8(61.5)$ & - \\
\hline $\begin{array}{l}\text { Hormone therapies } \\
\text { Tamoxifen }\end{array}$ & $12(92.7)$ & $9(69.2)$ & - \\
\hline $\begin{array}{l}\text { Aromatase } \\
\text { inhibitors }\end{array}$ & $12(92.3)$ & $1(7.7)$ & - \\
$\begin{array}{l}\text { Fluvestrant } \\
\text { Everolimus }\end{array}$ & $5(38.4)$ & $8(61.5)$ & - \\
\hline Palbociclib & $5(38.4)$ & $7(53.8)$ & $1(7.7)$ \\
\hline
\end{tabular}

With regard to research, liaison and human resources training activities, most institutions have an internal ethics committee (11/13 [84.6\%]) and availability of resources for clinical trial monitoring and data management was heterogeneous (Table 6).
Table 5. Availability of complementary genetic testing for diagnosis

\begin{tabular}{|l|c|c|}
\hline \multirow{2}{*}{ Type of test } & \multicolumn{2}{|c|}{$\begin{array}{c}\text { Availability } \\
(\mathbf{n = 1 3 )} \mathbf{n}(\%)\end{array}$} \\
\cline { 2 - 3 } & Yes & No \\
\hline Hereditary cancer & $8(61.5)$ & $5(38.4)$ \\
\hline $\begin{array}{l}\text { For treatment decision } \\
\text { Oncotype }\end{array}$ \\
$\begin{array}{l}\text { MammaPrint } \\
\text { Endopredict }\end{array}$
\end{tabular}

\section{Discussion}

The care of patients with breast cancer requires the coordination of highly specialized resources and personnel, in order to provide patients with comprehensive and optimal care.

The lack of basic resources to treat breast cancer is evident, especially in terms of diagnostic equipment and most medications for treatment. 
Table 6. Research, liaison and human resources training activities

\begin{tabular}{|l|c|c|}
\hline & \multicolumn{2}{|c|}{$\begin{array}{c}\text { Availability } \\
(\mathbf{n}=13), \mathbf{n}(\%)\end{array}$} \\
\cline { 2 - 3 } & Yes & No \\
\hline $\begin{array}{l}\text { Participation in cooperative groups } \\
\text { Source of the conducted trials }\end{array}$ & $7(53.8)$ & $6(46.1)$ \\
\hline $\begin{array}{l}\text { Internal } \\
\text { External (industry) }\end{array}$ & $9(69.2)$ & $4(30.7)$ \\
\hline $\begin{array}{l}\text { Support to study protocols } \\
\text { Monitoring } \\
\text { Data management }\end{array}$ & $8(61.5)$ & $5(38.4)$ \\
\hline $\begin{array}{l}\text { Human resources training } \\
\text { Specialty residents* }\end{array}$ & $9(69.2)$ & $4(30.7)$ \\
\hline $\begin{array}{l}\text { High-specialty courses } \\
\text { *Surgical oncology, gynecologic oncology, medical oncology, radiation oncology. }\end{array}$ & $3(23.1)$ & $10(76.9)$ \\
\hline
\end{tabular}

Most institutions information was collected from, do have the essential disciplines for management (medical oncology, surgical oncology, breast radiology, palliative care, pathology and nutrition); however, there is a need to increase the availability of specialists in rehabilitation, genetics, plastic surgery and psycho-oncology, in order for a more comprehensive care to be provided. These deficiencies force some centers to refer patients somewhere else to complete their care, which generates treatment delay and compromises therapeutic outcomes. The option of outsourcing services the institutions lack, although it does not solve the underlying problem, can represent the difference of having access to a more complete service, which can result in a benefit for patients. It should be noted that the role of the geneticist is of utmost importance in our area, since up to $15 \%$ of cases are 40 years old or younger, and most of them are candidates for genetic testing.

Ideally, the sentinel node procedure should be carried out with radionuclide and dye; however, $61.5 \%$ of institutions have nuclear medicine, and the use of dyes such as patent blue has become highly expensive. In some centers, the patent blue dye is externally acquired by the treating doctors and/or patients because these type of supplies are not a priority for these hospitals. One option is using methylene blue dye, with very similar results to those obtained with other dyes, but the same prophylactic measures have to be taken into account due to the risk of anaphylactic reaction.

The training of human resources is a central issue to have the care brought to the places where it is required.
It is important for medical specialty residents, nursing staff and paramedical services to complete their training in centers with higher experience and prestige; however, the experience of this trainee personnel can be used to support the care of patients in places where currently there are no human resources training programs and patients are cared for.

At the administrative level, specific stimuli could be promoted in order for the type of specialists some cities of the country lack find it attractive to go there and complete the treatment teams. Although in this study the focus was on breast cancer, many of the specialists the institutions lack can also provide services to patients with other pathologies.

One of the main limitations of this study was low participation. Although the information was sent to 30 specialists who were previously sensitized about the importance of the work that was underway, participation did not exceed $44 \%$. Although $76.9 \%$ of the participating institutions have databases, some databases are incomplete or lack the necessary variables to be included in multicenter trials. SMeO's GCIMOs goal is to facilitate collaboration between clinical care and research centers, with the purpose to optimize resources and favor scientific productivity in order to improve patient care (in our case, with the GCIMO-M, the care of patients with breast cancer). It is necessary to broaden the representativeness of the sample by including more hospitals, since this way there will be a more representative picture of the reality in our country, thus facilitating requesting from the corresponding authorities the resources that are lacking based on real figures. In many hospitals, the same specialist resolves the deficiencies of his/her institution to solve the patient's diagnostic or therapeutic problem; however, this rescue measure translates into the hospital not realizing its deficiencies and the specialist not fully practicing within his/her field.

Information such as that presented in this paper makes it evident that it is necessary to strengthen clinical research activities at hospitals where it is carried out, particularly with regard to study monitoring and data management. Institutional collaboration in multicenter trials will enable optimizing resources, and will increase the number of participants in studies, as well as their national representativeness. According to the results of the questionnaire applied in this project, now we know the capability of each institution to participate in multicenter trials; however, the lack of resources (both of personnel and equipment and medications) 
limits the performance of larger projects that require more hospital infrastructure for the basic management of breast cancer.

\section{Acknowledgements}

The GCIMO-M thanks the institutions that participated in this study for their collaboration, as well as to their managers for allowing the provision of information. Sharing is the only way to know the reality of our country, since we assume that hospitals have the necessary infrastructure for the care of patients with breast cancer.

Roche Mexico contributed supporting the copyediting through ILS Clinical Research.

\section{Conflict of interests}

The authors declare not having any conflicts of interest.

\section{Additional material}

Supplementary material additional to this article can be found in its electronic version, available at https:// doi.org/10.24875/j.gamo.19000258

\section{References}

1. GLOBOCAN 2012: Estimated Cancer Incidence, Mortality and Prevalence Worldwide in 2012 [Internet]. Ginebra: World Health Organization, International Agency for Reasearch on Cancer [fecha de consulta: 1 de marzo de 2019]. Disponible en: http://globocan.iarc.fr/Pages/fact_ sheets cancer.aspx

2. Aldaco-Sarvide $F$, Pérez-Pérez $P$, Cervantes-Sánchez G, Torrecillas-Torres L, Erazo-Valle-Solís AA, Cabrera-Galeana $P$, et al. Mortalidad por cáncer en México: actualización 2015. Gac Mex Oncol. 2018;17:28-34.

3. Chavarri-Guerra Y, Villarreal-Garza C, Liedke PE, Knaul F Mohar A, Finkelstein DM, et al. Breast cancer in Mexico: a growing challenge to health and the health system. Lancet Oncol. 2012;13(8):e335-43.

4. Maffuz-Aziz A, Labastida-Almendaro S, Sherwell-Cabello S, Ruvalcaba-Limón E, Domínguez-Reyes CA, Tenorio-Torres JA, et al. Supervivencia de pacientes con cáncer de mama. Análisis por factores pronóstico, clínicos y patológicos. Ginecol Obstet Mex. 2016;84(8):498-506.

5. Consenso Mexicano sobre diagnóstico y tratamiento del cáncer mamario. Séptima revisión. Colima 2017 [Internet]. México: Masson Doyma México, S.A. [fecha de consulta: 1 de marzo de 2019]. Disponible en: http:// consensocancermamario.com

6. Reynoso-Noverón N, Mohar A. El cáncer en México: propuestas para su control. Salud Pública Méx. 2014;56(5):418-20. 